\title{
Preparative Separation of Lappaconitine from Aconitum leucostomum by HSCCC
}

\author{
Amatjan $A^{1,2}$, Slukhan $U^{3}$, Li $C^{1}$, Ke-Lin HU ${ }^{1}$ and Haji Akber Aisa ${ }^{1 *}$ \\ 'Xinjiang Technical Institute of Physics and Chemistry, Chinese Academy of Sciences, the Key Laboratory of Xinjiang Indigenous Medicinal Plants Resource Utilization,
Urumqi 830011 , China \\ ${ }^{2}$ Xinjiang Uyghur Aoutonomous Regin Institute for Food and Drug Control, Urumqi 830004, China \\ Institute of the Chemistry of Plant Substances, Academy of Sciences of the Republic of Uzbekistan, Tashken 700125, Uzbekistan
}

\begin{abstract}
This paper describes a system for the preparation of lappaconitine from Aconitum leucostmum Worosch., using HSCCC, and examines the effect of the two-immiscible solvent system (TISS) composed of chloroform- methanol- 0.2 $\mathrm{mol} / \mathrm{L}$ hydrochloric acid $(4: 1.5: 2)$. Under the optimized condition, about $75 \mathrm{mg}$ of lappaconitine, at a purity of $98 \%$ that was done by high performance liquid chromatography (HPLC), are obtained from $250 \mathrm{mg}$ of the crude alkaloid extract. The compound was checked by HPLC-UV, electrospray ionization mass spectrometry (ESI-MS), ${ }^{1} \mathrm{H}$ NMR and ${ }^{13} \mathrm{C}$ NMR.
\end{abstract}

Keywords: Aconitum leucostmum; Alkaloids; Preparative chromatography; High speed counter-current chromatography (HSCCC)

\section{Introduction}

Aconitum leucostomum Worosch., which is a kind of perennial plant (Ranunculaceae family), is popular herbs in the northwestern area of China as Xinjiang and Gansu province [1,2]. The Roots of A. leucostomum are externally used as a folk medicine to treat traumatic injury and rheumatic disease [3], and known to contain a large amount of diterpenoid alkaloids, such as $\mathrm{N}$-acetylsepaconitine, anthranoyllycoctonine, $\mathrm{N}$-deacetyllappaconitine, delcosine, delosine, 6, 14-dimethoxyfroesticine, lappaconitine, leucotines, leucotines A, leucotines B, lycaconitine, sepaconitine, etc. [4-6]. The major alkaloid, lappaconitine, was found to exhibit anti-inflammatory, tyrosinase inhibition and analgesic actions, and has been widely used as a pain reliever with neither toxic nor addictive [7-19] (Figure 1).

At present, the major diterpenoid alkaloids in A. leucostomum are often separated with conventional isolated techniques as both column chromatography and high- performance liquid chromatography or thin-layer chromatography (TLC), etc., but the methods present a challenge for irreversible adsorption, lower sample recovery and time consuming [4-7]. However, the other separation method like to HSCCC for it, which can be advantages of high efficiency and recovery, are none dealt with [20-22].

For HSCCC, extraction by the counter-current distribution principle is especially suited to the separation of components in a mixture under conditions where the differences in the partition coefficients $(K)$ are small. Thus, it is need to applied, where the method has distinct advantages over comparable multiple chromatographic techniques, to separate an alkaloid from each other. In addition, HSCCC can provide the analysis and separation method for the diterpenoid alkaloids where have a proton affinity and strong ultraviolet-visible absorption. Although the important step for the method is based upon partitioning of desired compounds between two immiscible solvent, it is focused on the stability and solubility, the acceptable ratio, the retention of the stationary phase $\left(R_{s}\right)$ and the suitable $K$ for target component $[21,23]$. To develop a suitable for diterpenoid alkaloids, $\mathrm{pH}$ is adjusting based on neutralization between mobile and stationary phases [24-26].

In this paper, we reported herein the separation and structural elucidation of lappaconitine in crude alkaloid extracts from the roots of A. leucostomum. The optimization of HSCCC separation condition is also discussed.

\section{Material and Methods}

\section{Plant material and reagents}

Whole plants of Aconitum leucostomum Worosch., collected in Burqin of Xinjiang of P.R. China, were identified by Professor Sheng Guan-ming at Xinjiang Institute of Ecology and Geography Chinese Academy of Sciences.

Methanol and chloroform were HPLC-grade reagents for HPLC purchased from Fisher Scientific Company (Fair Lawn, NJ, USA) and filtered with $0.45 \mu \mathrm{m}$ filter. Other chemicals and solvents were of analytical grade purchased from Tianjin Chemical Factory (Tianjin, China).

\section{Instruments}

HSCCC were acquired using a model TBE-300 A high-speed countercurrent chromatograph (Shanghai Tauto Biotech Co., Shanghai, China) equipped with three polytetrafluoroethylene (PTFE)

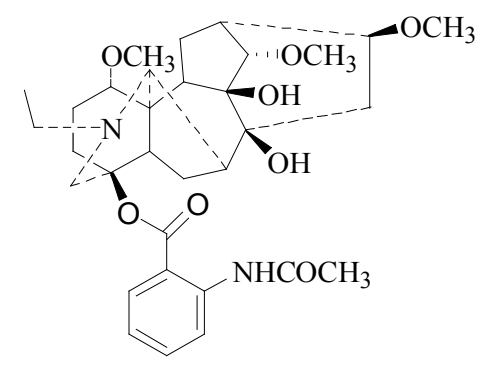

Figure 1: Chemical structure of lappaconitine.

*Corresponding author: Haji Akber Aisa, Xinjiang Technical Institute of Physics and Chemistry, Chinese Academy of Sciences, the Key Laboratory of Xinjiang Indigenous Medicinal Plants Resource Utilization, Urumqi 830011, China, Tel: +869913835679; E-mail: haji@ms.xjb.ac.cn

Received March 14, 2017; Accepted March 22, 2017; Published March 27, 2017

Citation: Amatjan A, Slukhan U, Li C, Ke-Lin HU, Aisa HA (2017) Preparative Separation of Lappaconitine from Aconitum leucostomum by HSCCC. Nat Prod Chem Res 5: 258. doi: 10.4172/2329-6836.1000258

Copyright: (c) 2017 Amatjan A, et al. This is an open-access article distributed under the terms of the Creative Commons Attribution License, which permits unrestricted use, distribution, and reproduction in any medium, provided the original author and source are credited. 
multilayer coils (i.d.: $2.6 \mathrm{~mm}$, total volume: $290 \mathrm{~mL}$ ) on the rotary frame $5.0 \mathrm{~cm}$ from the central axis of the centrifuge, and a $20-\mathrm{mL}$ manual sample loop. $\beta$ value ranged from 0.5 for the internal terminal to 0.8 for the external terminal. $\beta=r / R$, where $r$ is the distance from the column holder axis to the coil and $R$ is the distance from the column holder axis to the centrifuge axis. In addition, HSCCC was also carried out on a model TBP-50 A constant-flow pump (Shanghai Tauto Biotech, Shanghai, China) and 8823A-UV Monitor (Institute of New Technology Application, Beijing, China) at $254 \mathrm{~nm}$. Model N 2000 chromatography software package (Zhejiang University, Hangzhou, China) was used for instrument control, date acquisition and processing.

HPLC system carried out on a Dionex LC system consisting of a 4-solvent delivery system P 680 type, an ASI-100 automated sample injector, a TCC-100 thermostatted column compartment, and a UVD $170 \mathrm{U}$ detector and a Chrome Leon Work Station. Analytical TLC was performed using $\mathrm{Si}$ gel $60 \mathrm{~F}_{254}$ precoated glass plates $(0.25 \mathrm{~mm}$ layer thickness, $10 \times 10 \mathrm{~cm}$ ).

The mass spectrometry used here was a 4000 QTRAP LC/MS/MS (Applied Biosystems, USA). The ${ }^{1} \mathrm{H}$ spectra were recorded on Inova-600 superconducting NMR spectrometer (Varian, Palo Alto, CA, USA) using a 5-mm sample tube. The ${ }^{13} \mathrm{C}$, APT, COSY, NOESY, HSQC, and HMBC NMR experiments were run standard pulse sequences, with TMS was used as an internal standard.

\section{Preparation of crude alkaloid extracts}

The air-dried, ground roots of A. leucostomum (1.8 kg) were powdered and extracted with $80 \%$ ethanol solution $(2 \times 10 \mathrm{~L})$ under reflux at $80^{\circ} \mathrm{C}$ for $2 \mathrm{~h}$. Then the extracts were combined and concentrated under reduced pressure at $60^{\circ} \mathrm{C}$. The concentrated residue was suspended in water (1:3), and then partitioned with chloroform three times (each times $1 \mathrm{~L}$ ). The organic layers were combined and concentrated under reduced pressure at $40^{\circ} \mathrm{C}$ to give a chloroformsoluble residue, and acidified with $5 \%$ aqueous $\mathrm{H}_{2} \mathrm{SO}_{4}$ solution, after removal of the acid-soluble material, re-basified with $\mathrm{Na}_{2} \mathrm{CO}_{3}$ to 7.0 and 10.0, and then successively partitioned with chloroform to obtain 7.89 $\mathrm{g}$ (in $\mathrm{pH} 7.0, \mathrm{C} 001$ ) and $1.38 \mathrm{~g}$ (in $\mathrm{pH} 10.0, \mathrm{C002}$ ) of two chloroformsoluble crud alkaloidal residues. The crude alkaloidal residue (in $\mathrm{pH}$ 7.0, C001, $7.89 \mathrm{~g}$ ) was dissolved in acetone and filtered, and then concentrated to give crude alkaloid $7.38 \mathrm{~g}$.

\section{Selection of the two-phase solvent system}

HSCCC separations using of the two immiscible solvents composed of chloroform, methanol and dilute $\mathrm{HCl}$ at volume ratios $4: 1.5: 2$ to $4: 3: 2$, and thoroughly equilibrating in a separatory funnel at room temperature. The composition of two-phase solvent system was selected as $K$ values, which were also determined by HPLC, is especially suitable from 0.5 to 2.0 for the desired compounds in crude alkaloid extract. About $0.5 \mathrm{mg}$ of crude example was added to $4.0 \mathrm{~mL}$ of an equal volume mixture of the aqueous (upper) phase and the organic (lower) phase, and dissolved. The tube agitated to allow thorough mixing, after equilibrating at room temperature, the upper and lower phase were prepared for HPLC analysis. Then, $K$ value is evaluated by both the peak area of a desired substance in the upper phase $\left(\mathrm{A}_{U}\right)$ and the lower phase $\left(\mathrm{A}_{\mathrm{L}}\right)$. This is shown as $K=A_{\mathrm{U}} / A_{\mathrm{L}}$.

\section{HSCCC separation}

Two immiscible solvents for HSCCC separation was used of a mixture of 4 volumes of chloroform, 1.5 volumes of methanol and 2 volumes of $0.2 \mathrm{~mol} \cdot \mathrm{L}^{-1} \mathrm{HCl}$. At each operation, the solvents will be thoroughly mixed, and degassed by sonication for $30 \mathrm{~min}$ shortly before use. The sample solution was prepared by dissolving $60 \mathrm{mg}$ of crude sample in $10 \mathrm{~mL}$ mixture of 5 volumes of upper phase and 5 volumes of lower phase.

HSCCC separation was carried out preparative using the following procedure. First, for the lower phase (as mobile phase) pumped into the column at a flow-rate of $4.0 \mathrm{~mL} / \mathrm{min}$, while the apparatus was run at e revolution speed of $800 \mathrm{r} / \mathrm{min}$. For hydrodynamic equilibrium of two immiscible solvents, as the mobile phase had been eluted from the tail outlet, had been reached (about $1 \mathrm{~h}$ later), then sample solution was injected, the peaks of interest were online detected at $254 \mathrm{~nm}$. According to the peak chromatogram, each peak fraction was manually collected and then evaporated under reduced pressure. The residue was dissolved in methanol before proceeding with chromatographic analysis of HPLC.

\section{TLC and reverse-phase HPLC-UV analysis}

In this experiment, the crude extract, and the peak fraction from HSCCC separation was analyzed by TLC, with the solvent system composed of chloroform and methanol (5:1), and HPLC. For the sample solution, were dissolved $3.0 \mathrm{mg}$ of the substance to be examined in methanol, sonicate if necessary. These were detected by TLC as blue spot prior to spraying under short-wave UV light using chloroformmethanol (5:1). The analysis was performed on YWC ODS-A column $(250 \times 4.6 \mathrm{~mm}, 5.0 \mu \mathrm{m})$ at $27^{\circ} \mathrm{C}$ with flow-rate of $1.0 \mathrm{~mL} / \mathrm{min}$. The mobile phase was composed of methanol, water, chloroform, and TEA (70:30:2:0.1). The auto-sampler was conditioned at $4^{\circ} \mathrm{C}$ and injection volume was $10 \mu \mathrm{L}$ for sample injection. The peaks of interest were monitored with UV absorbance at $238 \mathrm{~nm}$ of wavelengths.

\section{Identification of target compound}

In ESI-MS analysis, ESI source was operated in positive ionization mode, and mass spectrometry detector parameters were as follows: desolvent gas temperature at $300^{\circ} \mathrm{C}$; nitrogen flow rate, $500 \mathrm{~L} / \mathrm{h}$; source temperature, $120^{\circ} \mathrm{C}$; capillary voltage, $4.0 \mathrm{kV}$; cone voltage, $25.0 \mathrm{~V}$; mass scan from $m / z 100$ to 1000 . All date was processed using Analyst 1.4.2 software. The structural identification of the peak fraction of HSCCC was elucidated by means of ${ }^{1} \mathrm{H}$ and ${ }^{13} \mathrm{C}$ NMR, COSY, NOESY, HSQC, and HMBC NMR experiments.

\section{The target compound exhibited the flowing date}

Amorphous powder, M.P 218-220 ${ }^{\circ}$ C; ESI-MS $m / z: 585.2[\mathrm{M}+\mathrm{H}]^{+}$ $567.2\left[\mathrm{M}-\mathrm{H}_{2} \mathrm{O}\right]^{+}, 535.2\left[\mathrm{M}-\mathrm{OCH}_{3}-\mathrm{H}_{2} \mathrm{O}\right]^{+}, 406.1\left[\mathrm{M}-\mathrm{C}_{9} \mathrm{H}_{8} \mathrm{NO}_{3}\right]^{+}, 388.1$ $\left[\mathrm{M}-\mathrm{C}_{9} \mathrm{H}_{8} \mathrm{NO}_{3}-\mathrm{H}_{2} \mathrm{O}\right]^{+}, 161.5\left[\mathrm{M}-\mathrm{C}_{23} \mathrm{H}_{36} \mathrm{NO}_{5}-\mathrm{OH}\right]^{+} ;{ }^{1} \mathrm{H}$ NMR $(600 \mathrm{MHz}$, $\left.\mathrm{CDCl}_{3}\right) \delta: 10.84\left(1 \mathrm{H}, \mathrm{s}, \mathrm{NHCOCH}_{3}\right), 8.67\left(1 \mathrm{H}, \mathrm{d}, J=8.4 \mathrm{~Hz}, \mathrm{H}-3^{\prime}\right), 7.84$ $\left(1 \mathrm{H}, \mathrm{d}, J=7.8 \mathrm{~Hz}, \mathrm{H}-6^{\prime}\right), 7.47\left(1 \mathrm{H}, \mathrm{dd}, J=7.8\right.$ and $\left.7.8 \mathrm{~Hz}, \mathrm{H}-4^{\prime}\right), 7.03$ (1 $\mathrm{H}, \mathrm{dd}, J=7.8$ and $\left.7.8 \mathrm{~Hz}, \mathrm{H}-5^{\prime}\right), 3.57\left(2 \mathrm{H}\right.$, br.s, $\left.\mathrm{H}-1, \mathrm{H}-21_{\beta}\right), 3.56(1 \mathrm{H}, \mathrm{s}$, $\mathrm{H}-14), 3.48$ (1 H, s, H-17), $3.46\left(3 \mathrm{H}, \mathrm{s}, \mathrm{OCH}_{3}-14\right), 3.42\left(3 \mathrm{H}, \mathrm{s}, \mathrm{OCH}_{3}-\right.$ 1), $3.34\left(3 \mathrm{H}, \mathrm{s}, \mathrm{OCH}_{3}-16\right), 3.29(1 \mathrm{H}, \mathrm{dd}, J=8.4$ and $7.8 \mathrm{~Hz}, \mathrm{H}-16), 3.25$ $\left(1 \mathrm{H}, \mathrm{s}, \mathrm{H}-19_{\beta}\right), 3.07\left(1 \mathrm{H}, \mathrm{s}, \mathrm{H}-6_{\beta}\right), 3.02\left(1 \mathrm{H}, \mathrm{s}, \mathrm{H}-3_{\beta}\right), 2.94(1 \mathrm{H}, \mathrm{d}, J=$ $\left.6.6 \mathrm{~Hz}, \mathrm{H}-19{ }_{\alpha}\right), 2.51(1 \mathrm{H}, \mathrm{d}, J=4.8 \mathrm{~Hz}, \mathrm{H}-13), 2.43(1 \mathrm{H}, \mathrm{d}, J=6.6 \mathrm{~Hz}$, H-7), 2.34 (3 H, m, H-5, H-15, H-21 $\left.{ }_{\alpha}\right), 2.24\left(3 \mathrm{H}, \mathrm{s}, \mathrm{NHCOCH}_{3}\right), 2.23$ $\left(2 \mathrm{H}, \mathrm{d}, J=11.4 \mathrm{~Hz}, \mathrm{H}-12_{\alpha}, \mathrm{H}-15_{\alpha}\right), 2.15\left(1 \mathrm{H}, \mathrm{d}, J=12 \mathrm{~Hz}, \mathrm{H}-2_{\beta}\right)$, $1.72\left(1 \mathrm{H}, \mathrm{m}, \mathrm{H}-6_{\beta}\right), 1.56(1 \mathrm{H}, \mathrm{d}, J=12 \mathrm{~Hz}, \mathrm{H}-2), 1.54(1 \mathrm{H}, \mathrm{d}, J=$ $\left.11.4 \mathrm{~Hz}, \mathrm{H}-3_{\beta}\right), 1.50\left(3 \mathrm{H}, \mathrm{s}, \mathrm{NHCH}_{2} \mathrm{CH}_{3}\right) ;{ }^{13} \mathrm{C} \mathrm{NMR}\left(150 \mathrm{MHz}, \mathrm{CDCl}_{3}\right)$ $\delta_{\mathrm{C}}: 79.8$ (C-1), 28.0 (C-2), 29.6 (C-3), 84.7 (C-4), 48.9 (C-5), 26.5 (C6), 46.9 (C-7), 75.0 (C-8), 80.7 (C-9), 47.0 (C-10), 50.5 (C-11), 23.4 (C-12),36.4(C-13), 89.1(C-14), 43.9(C-15), 82.3(C-16), 61.1(C-17), 56.4 (C-19), $50.5\left(\mathrm{NCH}_{2} \mathrm{CH}_{3}\right), 10.5\left(\mathrm{NCH}_{2} \underline{\mathrm{CH}}_{3}\right), 56.4\left(\mathrm{OCH}_{3}-1\right), 58.0$ $\left(\mathrm{OCH}_{3}-14\right), 56.3\left(\mathrm{OCH}_{3}-16\right), 166.6(\mathrm{OCO}), 114.4\left(\mathrm{C}-1^{\prime}\right), 142.0\left(\mathrm{C}-2^{\prime}\right)$, 
120.5 (C-3'), 135.2 (C-4'), 122.4 (C-5'), 130.7 (C-6'), 169.3 (NHCO), $25.6\left(\mathrm{NHCOCH}_{3}\right)$. Comparison of the physical and spectral date obtained for the compound with literature values established the structure of this diterpenoid alkaloid as lappaconitine [3-7,17-19].

\section{Results and Discussion}

\section{HPLC analyses}

The crude alkaloid extract of the aired, ground roots of $A$. leucostomum was fractionated by solvent partitions, and was assigned by means of HPLC-UV as described in the experimental section. A combination of CC and semi-preparative HSCCC allowed the isolation of lappaconitine from the $\mathrm{CHCl}_{3}$-soluble fraction.

\section{Chromatographic preparation}

In separation by HSCCC, A successful, is focused on the selection of a suitable two phase solvent system, as which according to $K$ values $(0.5$ 2.0) for each desired component. However, separation by HSCCC employing the solvent system of chloroform, methanol, and dilute hydrochloric acid $(\mathrm{HCl})$ systematically selected from 4:3:2 (v/v/v) to 4:1.5:2 (v/v/v) and the concentration of $\mathrm{HCl}$ from 0.2 to $0.3 \mathrm{~mol} \cdot \mathrm{L}^{-1}$, are investigated and shown in Table 1 . The result indicated that the volume of methanol and concentration of $\mathrm{HCl}$ on the solvent system for the target compound are most important factor whereas a gradual decrease in the volume ratio of methanol and increase in the concentration of $\mathrm{HCl}$ yielded a better resolution in Table 1 and Figure 2.

In addition, the $K$ values is that was to more than 1.3 in this system. According to above, the two-phase solvent system for the target compound composed of chloroform-methanol- $0.2 \mathrm{~mol} \cdot \mathrm{L}^{-1} \mathrm{HCl}$ (4:1.5:2, v/v/v) gave a suitable $K$ values, $R_{s}$ and resolution for the target compound, in Table 1.

\begin{tabular}{|c|c|c|c|}
\hline Solvent systems & $\boldsymbol{K}$ values & $\boldsymbol{R}_{\mathbf{s}}(\%)$ & Resolution \\
\hline $\mathrm{CHCl}_{3}-\mathrm{MeOH}-0.3 \mathrm{~mol} / \mathrm{L} \mathrm{HCl} \mathrm{(4:3:2)}$ & 2.60 & 75.1 & 0.67 \\
\hline $\mathrm{CHCl}_{3}-\mathrm{MeOH}-0.2 \mathrm{~mol} / \mathrm{L} \mathrm{HCl}(4: 3: 2)$ & 2.37 & 75.2 & 0.71 \\
\hline $\mathrm{CHCl}_{3}-\mathrm{MeOH}-0.3 \mathrm{~mol} / \mathrm{L} \mathrm{HCl}(4: 2: 2)$ & 1.97 & 78.7 & 0.86 \\
\hline $\mathrm{CHCl}_{3}-\mathrm{MeOH}-0.2 \mathrm{~mol} / \mathrm{L} \mathrm{HCl}(4: 2: 2)$ & 1.80 & 78.7 & 1.02 \\
\hline $\mathrm{CHCl}_{3}-\mathrm{MeOH}-0.3 \mathrm{~mol} / \mathrm{L} \mathrm{HCl} \mathrm{(4:1.5:2)}$ & 1.64 & 76.3 & 1.35 \\
\hline $\mathrm{CHCl}_{3}-\mathrm{MeOH}-0.2 \mathrm{~mol} / \mathrm{L} \mathrm{HCl}(4: 1.5: 2)$ & 1.38 & 76.2 & 1.75 \\
\hline
\end{tabular}

Table 1: The $K$ values and resolution of lappaconitine in several solvent systems for HSCCC.

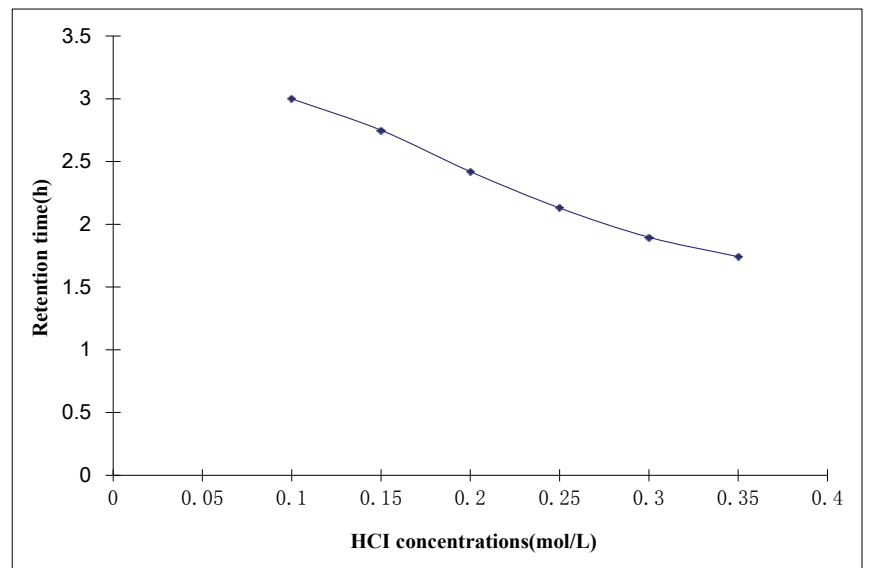

Figure 2: Comparison of retention time at the different given concentration of $\mathrm{HCl}$ by HSCCC.
Other factors, such as flow rate of mobile phase, column temperature, and revolution speed, were also investigated and optimized. As seen from Figure 3, it can be seen that the target compound resolution decreased as the flow rate of mobile phase from 5 to 2 increases the separation of the compound, but it took a little longer, and the more mobile phase was needed with the peak tailing of the target compound. Among those, the flow rate of mobile phase is performed more rapidly (as $4.0 \mathrm{~mL} / \mathrm{min}$ ) for HSCCC separation. The column temperature has significant effect on $K$ values and $R_{s}$. In present work, it was set at $25^{\circ} \mathrm{C}$. Finally, the revolution speed of the multilayer coil separation column affects $R_{s}$. In this experiment, all separations were used at $850 \mathrm{r} / \mathrm{min}$.

In order to separate the desired compound from the alkaloid extracts from A. leucoetomum by HSCCC, the two-solvent systems composed of chloroform-methanol- $0.2 \mathrm{~mol} / \mathrm{L} \mathrm{HCl}$ (4:1.5:2) was chosen first. Using the optimized conditions, about $75 \mathrm{mg}$ of peak 1 fraction are successfully obtained from $250 \mathrm{mg}$ of alkaloid extract from A. leucostomum by preparative HSCCC with a column capacity of 290 $\mathrm{mL}$ in less than $3 \mathrm{~h}$, and at a purity of $98 \%$ that done by HPLC, as shown in Figures 4, 5 and 6, and $R_{s}$ was $76 \%$.

\section{Structure identification of lappaconitine}

We isolated from the dry roots of A. leucostomum a known diterpenoid alkaloids, lappaconitine. It was identified by its physicochemical properties (M.P, ESI-MS, ${ }^{1} \mathrm{H}$ NMR, ${ }^{13} \mathrm{C}$ NMR) and chromatographic behaviors (TLC and HPLC).

Only a brief outline of the spectroscopic evidence for the structural assignment of lappaconitine has been published [6,7]. In a previous paper, its structure was assigned on basis of multinuclear $\left({ }^{1} \mathrm{H},{ }^{13} \mathrm{C}\right.$ and ${ }^{15} \mathrm{~N}$ ) high-field NMR and MS results $[18,19]$. The ${ }^{1} \mathrm{H}$ and ${ }^{13} \mathrm{C}$ NMR spectral date of lappaconitine were in accord with the reported values in the literature [16-19] and further details are provided in the following paragraphs.

The compound was obtained as an amorphous powder, and its molecular ion obtained at $m / z 585.2[\mathrm{M}+\mathrm{H}]^{+}$by ESI-MS. The compound displayed a yellow spot on TLC under UV absorption at $360 \mathrm{~nm}$. Assignments of the ${ }^{1} \mathrm{H}$ - and ${ }^{13} \mathrm{C}-\mathrm{NMR}$ spectra of lappaconitine were facilitated by performing ${ }^{1} \mathrm{H}^{-1} \mathrm{H}$ COSY and ${ }^{13} \mathrm{C}-{ }^{1} \mathrm{H}$ COSY which suggested the presence of three methoxyl (C-1, C-14 and $\mathrm{C}-16)$, two acetate groups $\left(\mathrm{NHCOCH}_{3}\right.$ and $\left.\mathrm{OC}=\mathrm{O}\right)$ and a $N$-ethyl group $\left(\mathrm{NCH}_{2} \mathrm{CH}_{3}\right)$. Thus, comparison of the physical and spectral

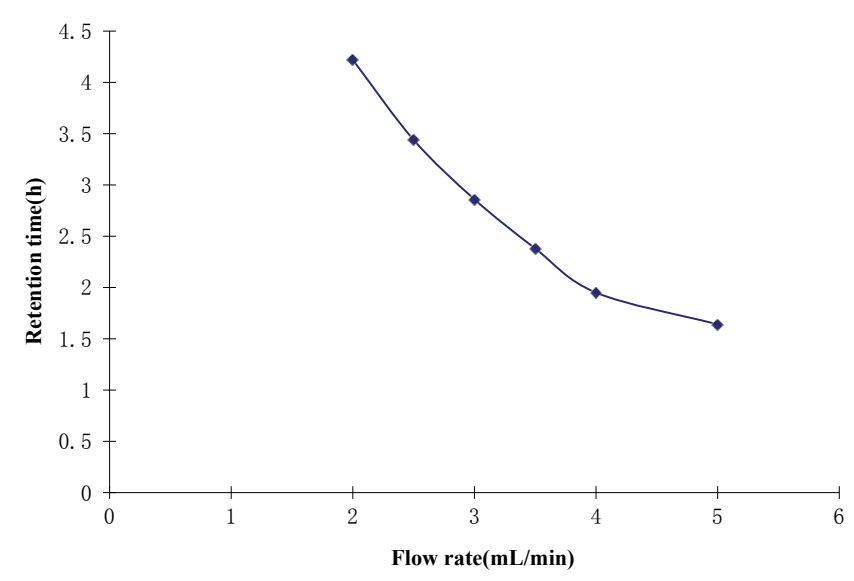

Figure 3: Comparison of retention time at the different given flow rate by HSCCC 


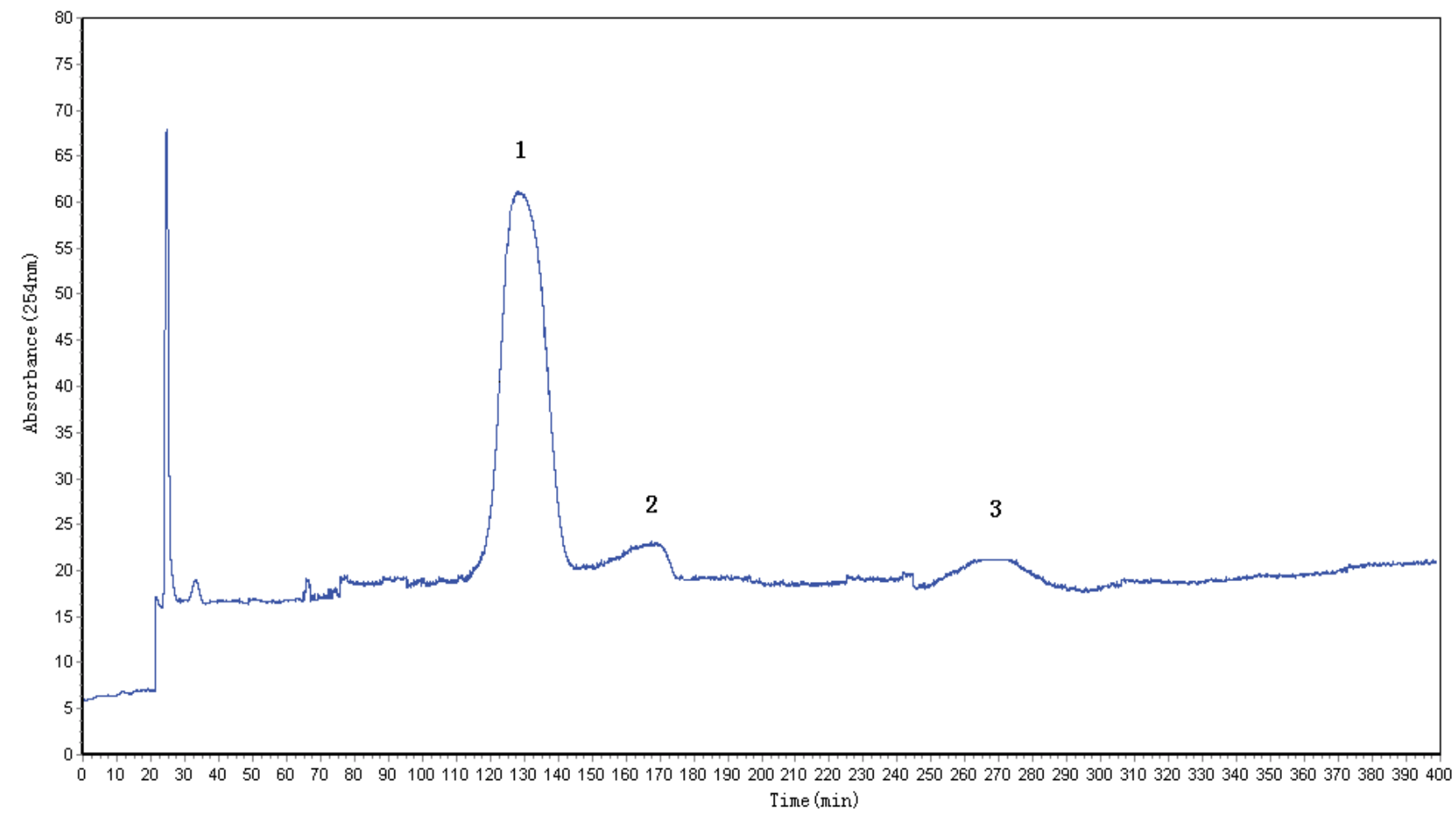

Figure 4: Chromatogram of the crud alkaloid extract from A. leucostomum by HSCCC

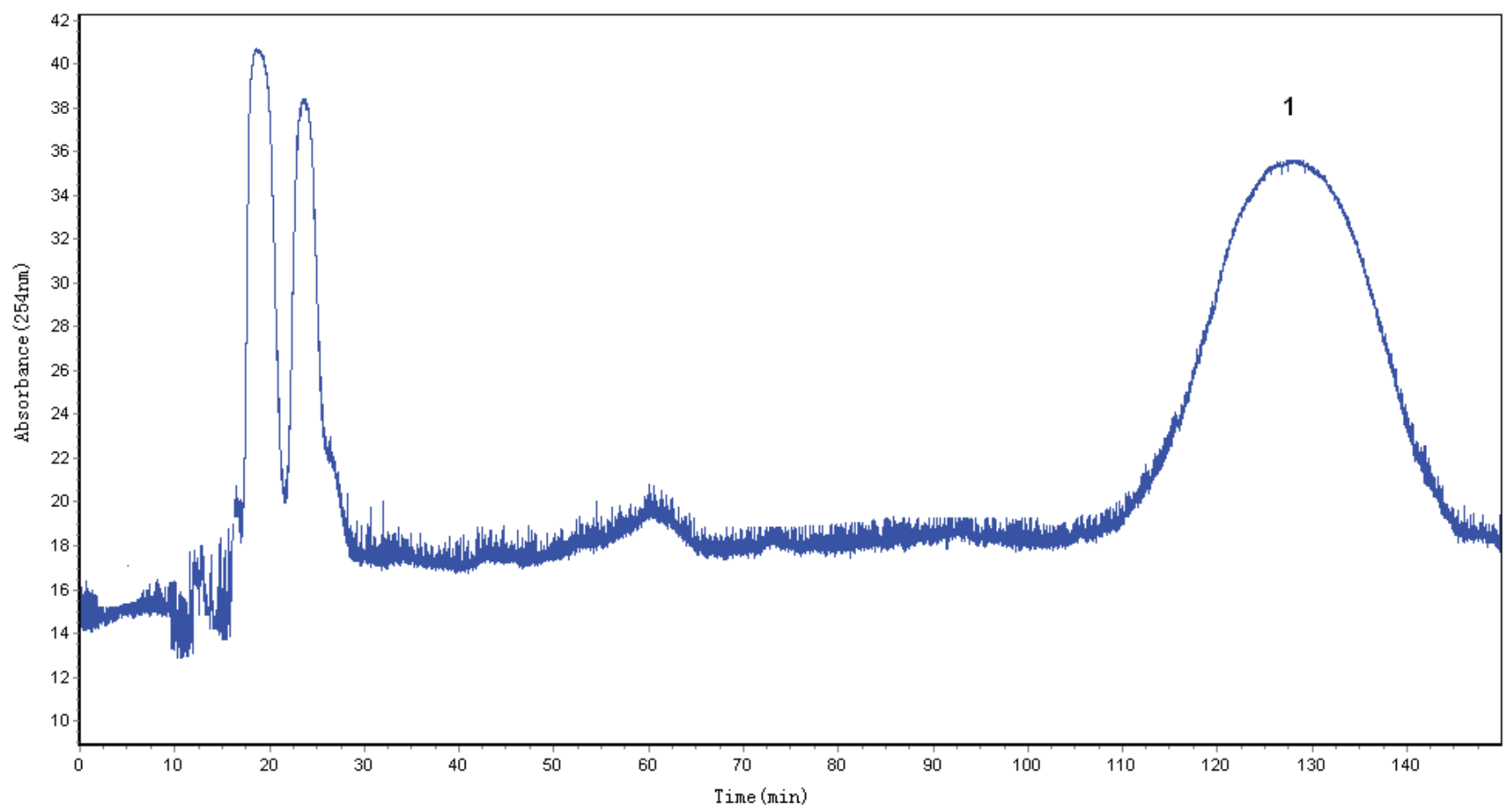

Figure 5: Chromatogram of lappaconitine of the crud alkaloid extract from A. leucostomum by HSCCC. 
Citation: Amatjan A, Slukhan U, Li C, Ke-Lin HU, Aisa HA (2017) Preparative Separation of Lappaconitine from Aconitum leucostomum by HSCCC. Nat Prod Chem Res 5: 258. doi: 10.4172/2329-6836.1000258

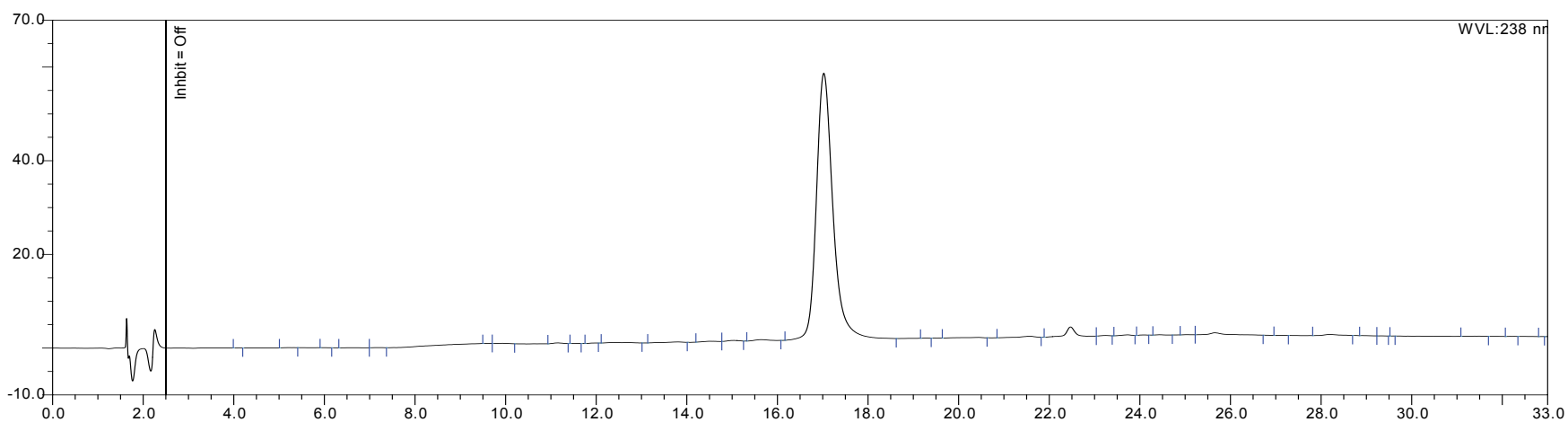

Figure 6: HPLC chromatogram of lappaconitine from the crud alkaloid extract from A. leucostomum.

date obtained for the compound with literature values established the structure of this diterpenoid alkaloid as lappaconitine [3-7,17-19].

\section{Conclusion}

A rapid, efficient, and economical HSCCC method for preparative isolation of lappaconitine from A. leucostomum was established. It was identified by its physicochemical properties (MP, ESI-MS, ${ }^{1} \mathrm{H}$ NMR, ${ }^{13} \mathrm{C} \mathrm{NMR}$ ) and chromatographic behaviors (TLC and HPLC). From the results of the HSCCC and HPLC method, we can conclude that the present method can be satisfactorily used as the reference substances for chromatography or bioactivity compound.

\section{Acknowledgements}

The study was supported by the CAS/SAFEA International Partnership Program for Creative Research Teams and by China National Funds for Distinguished Young Scientists No. 30925045

\section{References}

1. Editorial Committee for Flora of China of Chinese Academy of Sciences (1979) Flora of China, Science Press, Beijing, China 27: 171.

2. Yuanjie X, Yaning C, Weihong L, Aihong F, Xiaodong M, et al. (2010) Distribution pattern of plant species diversity in the mountainous region of Ili River Valley, Xinjiang. Environ Monit Assess, pp: 1-4.

3. Xiao-Yi W, Bi-Yu W, Zhang J (1995) Diterpenoid alkaloids from Aconitum leucostomum. Chinese Tradit Herb Druds 26: 344-346.

4. Tel'nov VA, Yunusov MS, Abdullaev ND, Zhamierashvili MG (1988) $\mathrm{N}$-acetylsepaconitine - a new alkaloid from Aconitum leucostomum. Chem Nat Compd 24: 472-475.

5. Jianmin Y, Jun X, Qinshi Z, Handong S, Yaozu C (1996) Diterpenoid alkaloids from Aconitum leucostomum. J Nat Prod 59: 277-279.

6. Tel'nov VA, Usmanova SK (1992) Leuconine - a new alkaloid from Aconitum leucostomum and A. septentrionale. Chem Nat Compd 28: 470-471.

7. Tel'nov VA, Usmanova SK, Abdullaev ND (1993) Structure of acsinatine. Chem Nat Compd 29: 346-348.

8. Ji-Zhi YU, Zhang BJ, Jiang XT (2005) Clinical application of lappaconitine hydrobromide. Acad J Sec Mil Med Univ 26: 822-824.

9. Xiu-Hua L, Yan-Bin S, Yu-Zhu G (2009) Stability of raw medicine of lappaconitine hydrobromide. China Pharmaceuticals 18: 21-22.

10. Ming-Pei L, Yang J, Yue-Lan D (2004) Anti-inflammatory effect of lappaconitine. Pharmacology and Clinics of Chinese Materia Medica 20: 13-15.

11. Farzana S, Manzoor A, Muhmud THK, Saima J, Asma E, et al. (2005) Alkaloids of Aconitum laeve and their anti-inflammatory, antioxidant and tyrosinase inhibition activities. Phytochemistry 66: 935-940.

12. Ming-Pei L (2003) Analgesic effect of Lappaconitine on inflammatory pain. Chinese Remedies \& Clinics 3: 244-245.
13. Dzhakhangirov FN, Sultankhodzhaev MN, Tashkhodzhaev B, Salimov BT (1997) Diterpenoid alkaloide as a new class of antiarrhythmic agents. StructureActivity Relationship. Chem Nat Compd 33: 190-202.

14. Heubach JF, Schüle A (1998) Cardiac effects of lappaconitine and $\mathrm{N}$-deacetyllappaconitine, two diterpenoid alkaloids from plants of the Aconitum and Delphinium species. Planta med 64: 22-26.

15. Gu-Ya K, De-Hua Q, Yan Q (2002) Study on the effects of Gao-Wu hydrobromide tablet on experimental arrhythmia. Sichuan of Physiological Sciences 24: 175-177.

16. Nikolai EP, Vladimir KK, Marc BT, Tatyana VL, Olga AL, et al. (2005) Mechanisms of photoinduced electron transfer reactions of lappaconitine with aromatic amino acids. Time-resolved CIDNP study. Org Biomol Chem 3 881-885.

17. Nikolay EP, Tatyana VL (2007) Redox reactions of natural alkaloid lappaconitine. Russ Chem Bull In 56: 631-642.

18. Nikolay EP, Tatyana VL, Alexey VT, Irina AN, Natalia AP (2008) Phototransformation products of the alkaloid lappaconitine: Multinuclear NMR study. J Photochem Photobiol A: Chemistry 197: 290-294.

19. Nikolay EP, Olga AS, Marc BT, Tatyana VL, Tatyana AK, et al. (2010) CIDNP and EPR study of phototransformation of lappaconitine derivatives in solution. J Phys Chem B 114: 4646-4651.

20. Ito Y, Conway WD (1996) High-Speed Countercurrent Chromatography. John Wiley \& Sons Inc., pp: 51-106.

21. Ren-Min L (2009) Application of High-Speed Counter-Current Chromatography in Separation of Natural Products. China Ocean University Press, Qingdao, China, p: 72.

22. Sutherland IA, Fisher D (2009) Role of counter-current chromatography in the modernisation of Chinese herbal medicines. J Chromatogr A 1216: 740-753.

23. Ito $Y$ (2005) Golden rules and pitfalls in selecting optimum conditions for highspeed counter-current chromatography. J Chromatogr A 1065: 145-168.

24. Fuquan Y, Yoichiro I (2001) pH-Zone-refining counter-current chromatography of lappaconitine from Aconitum sinomontanum nakai I. Separation of prepurified extract. J Chromatogr A 923: 281-285.

25. Fuquan Y, Yoichiro I (2002) Preparative separation of lappaconitine ranaconitine, $\mathrm{N}$-deacetyllappaconitine and, $\mathrm{N}$-deacetylranaconitine from crude alkaloids of sample Aconitum sinomontanum Nakai by high-speed countercurrent chromatography. J Chromatogr A 943: 219-225.

26. Kai J, Chun-Hua Y, Jing-Han L, Qing-Fa T (2006) Isolation and identification of hetisine-type alkaloids from Aconitum coreanum by high speed countercurrent chromatography. Acta Pharm Sin 41: 128-131. 